\title{
The protective role of Gallic acid in Cisplatin nephrotoxicity
}

\section{Ebtesam S. Kotb ${ }^{a \star}$, Waleed M. Serag ${ }^{a}$, Reda F. M. Elshaarawy ${ }^{a}$, Hani S. Hafez ${ }^{b}$ and Zakaria El-Khayat ${ }^{c}$}

${ }^{a}$ Chemistry Department, Faculty of Science, Suez University, Suez, Egypt.

${ }^{b}$ Department of Zoology, Faculty of Science, Suez University, Suez, Egypt.

${ }^{c}$ Medical biochemistry department, National Research Center, Egypt.

\section{ARTICLE INFO}

Article history:

Received 27 May 2021

Accepted 1 June 2021

Available online 4 June 2021

\section{Keywords}

Nephrotoxicity,

Cisplatin,

DNA damage,

Gallic acid,

Antioxidant.
Received in revised form 1 June 2021

\begin{abstract}
Background: Nephrotoxicity is considered one of the most serious and dose-limiting factors for restricting clinical use of Cisplatin and anticancer efficacy. Gallic acid is a non-toxic substance that has a wide range of therapeutic roles with high antioxidant activity. So, the present study aims to investigate the concurrent protective action of Gallic acid against inflammatory and oxidative damage caused by Cisplatin in rat kidneys. Material and methods: Thirty-two male albino rats were classified into four groups, eight per each as follows: Group 1 (Normal control group): without treatment. Group 2 (Gallic acid group): healthy rats were given Gallic acid. Group 3 (Cisplatin group): healthy rats were injected with Cisplatin. Group 4 (Gallic acid + Cisplatin) treated group. Kidney functions, Paraoxonase-1, and inflammatory cytokines such as Tumor Necrosis Factor $\alpha$, respectively were determined. Results: Cisplatin was induced kidney damage with a high significance $(P<0.001)$ regarding kidney function tests and the group of Cisplatin + Gallic acid demonstrated a broad range in the prevention and/or management of kidney damage with a high significance $(P<0.001)$ compared to cisplatin group. Conclusion: Gallic acid has a protective role against kidney dysfunction and renal damage in Cisplatin therapy.
\end{abstract}

\section{Introduction}

Chemotherapy has provided new opportunities for improving the quality of life among cancer patients with cancer treatment emphasis. On the other side, treatment with some of the most successful cancer medications, despite its efficacy, showed a range of clear toxic symptoms (El-Sayed et al., 2008). Moreover, highly distributed exogenous toxicants such as antibiotics, chemotherapy, and radiotherapy have recorded high nephron-toxicity levels with high risk factors leading to kidney damage. Cisplatin is considered among the most commonly used chemotherapy medications and is one of the most common kidney toxicants (Xiang et al., 2019). Kidney damage and dysfunction due to Cisplatin chemotherapy are considered as one of the primary successful downsides among cancer patients with a wide range rate all over the world (Sri Laasya et al., 2020). Cisplatin is an inorganic molecule that is commonly used for chemotherapy with a chemical organized structure of platinum atom surrounded by two chloride and two ammonium atoms in the cis position.

\footnotetext{
* Corresponding authors at: Suez University

E-mail addresses: ebtsam.samir@suezuniv.edu.eg

(Ebtesam S. Kotb)
}

Additionally, Cisplatin is unlike most cancer therapy drugs which are typical with complex organic compounds (Figure 1), (Sánchez-González et al., 2011).

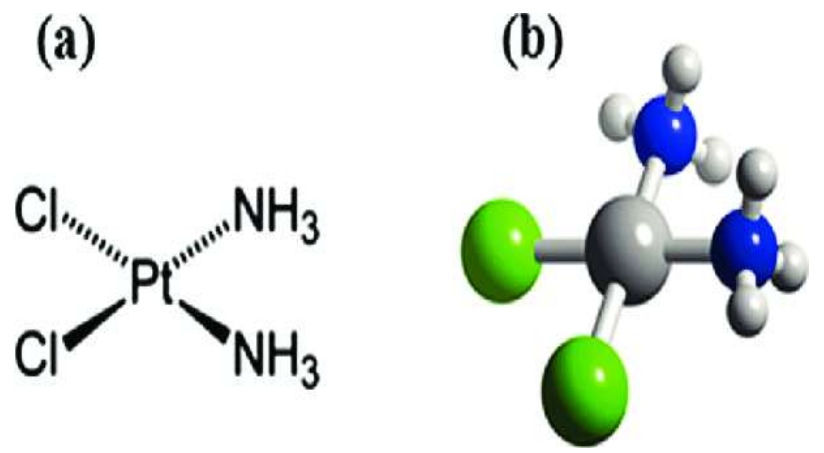

Figure (1) (Hassan et al., 2013). (a) The chemical structure of the Cisplatin (b)Presents the 3D structure of Cisplatin.

Although, Cisplatin has been a hallmark for cancer therapy; its use has been largely limited due to the emergence of acquired resistance and pathophysiological side effects to normal tissues such as neurotoxicity, and nephrotoxicity (Zhu et al., 2015; Monleón et al., 2017). Polyphenols, mainly flavonoids, and phenolic acids such as Gallic acid, exhibit antioxidant properties due to their hydrogen-donating and metal-chelating capacities 
(Scalbert and Williamson, 2000). Although, the nephrotoxicity mechanisms are not fully assumed; apoptosis, oxidative stress, and inflammation have been stated as the main cause for the development and exacerbation of kidney injury. Tumor Necrosis Factor $\alpha$ (TNF- $\alpha$ ) and Nuclear Factor-kB (NF-kB) play a decisive role in the inflammatory signaling pathways leading to proinflammatory cytokine and chemokine production and cell infiltration, which exacerbates kidney injury (El-Garhy et al., 2014; Ueki et al., 2013). Paraoxonases (PONs) are expressed in the liver and kidney and bounding to highdensity lipoproteins (HDLs) in the circulation (Francisco et al., 2018). They were identified as hydrolyzing enzymes that acting as antioxidants with a high affinity to exogenous toxic organophosphate compounds such as insecticide paraoxon. They are classified into three members Paraoxonase 1 (PON1), Paraoxonase 2 (PON2), and Paraoxonase 3 (PON3) that encoded by three separate genes on the same chromosome (Primo-Parmo et al., 1996; Harel et al., 2004; Binita et al.,2009).

Gallic acid (GA) (3,4,5-trihydroxybenzoic acid), (Figure 2 ), is a polyphenolic compound that is naturally extensively dispersed in gallnuts, green tea, grapes, red wine, apple peels, oak bark, tea leaves, sumac, mango, lemon, different berries, areca nut, pineapples, strawberries, bananas, and other fruits (Safaei et al., 2018 and OlaDavies et al., 2018). GA and its derivatives have shown a wide range of beneficial effects in the prevention and/or management of a variety of diseases due to its high antioxidant activities (Kahkeshani et al., 2019).

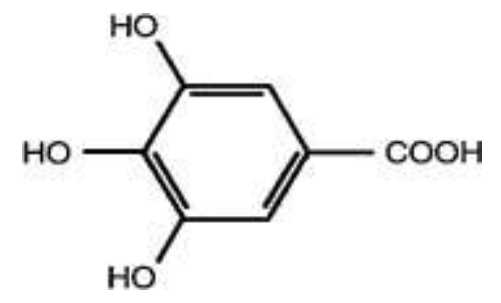

Figure (2): Chemical structure of Gallic acid (3,4,5trihydroxybenzoic acid) (Reckziegel et al., 2016).

The present study aims to investigate the effect of Cisplatin on kidney function and the protective role of Gallic acid.

\section{Materials and methods:}

\section{Materials:}

\section{A. Chemicals, reagents, and kits}

Gallic Acid $99.5 \%$ extra pure was purchased from Oxford (India). Cisplatin (Cisplatin $®$ Mylan $50 \mathrm{ml}$ vial) was obtained from Oncotec Pharma Produktion G.m.b.H., (Germany). Rat ELISA kits of TNF- $\alpha$ were purchased from Sun Long Biotech Co. Ltd., China. The paraoxonase-1 activity was determined by an adaptation of the spectrophotometric method of Gan et al., (1991) with modifications according to Kumar\& Rizvi (2014).

B. Experimental animals

32 male rats were used from the animal house of National Research Center (NRC) weighing from 120-150 g.
Animals were kept under a 12-hour light/12-hour dark period for 7 days in stainless steel cages at a temperature of $22 \pm 2{ }^{\circ} \mathrm{C}$, according to the ethical approval and regulations of NRC.

\section{Methods:}

A. Induction of nephrotoxicity

Rats were injected with a single intraperitoneal dose (i.p.) with Cisplatin of $12 \mathrm{mg} / \mathrm{kg}$ body weight according to Dizaye (2012).

\section{B. Experimental design}

Animals were divided into four groups eight per each as follows:

- Group 1 (Normal control group): negative control.

- Group 2 (Gallic acid group): healthy rats were intraperitoneally injected with Gallic acid with a dose of $40 \mathrm{mg} / \mathrm{kg}$ body weight/day for 14 days according to Akomolafe et al., (2014).

- Group 3 (Cisplatin group): healthy rats were injected i.p with Cisplatin $(12 \mathrm{mg} / \mathrm{kg}$ body weight) on the tenth day during the experimental period to induce nephrotoxicity according to Dizaye (2012).

- Group 4 (Gallic acid + Cisplatin) treated group: rats were given Gallic acid (40 mg/kg body weight; i.p.) for ten days, then on the tenth day of the study, rats were given Cisplatin (12 mg/kg body weight; i.p.) an hour after receiving the dose of Gallic acid, and then rats were given Gallic acid $(40 \mathrm{mg} / \mathrm{kg}$ body weight; i.p.) daily for another four days.

Blood was drawn from each rat 24 hours after the experiment period for the measurement of different biochemical parameters. Rats were then sacrificed, and kidneys were quickly removed, washed with cold saline solution $(0.9 \% \mathrm{NaCl})$, and then one kidney was homogenized as described by Hussein et al., (2013) for determination of oxidative stress parameter.

\section{Biochemical analysis:}

1- Kidney functions including serum creatinine was determined by the kinetic method according to Larsen (1972). Blood urea was estimated by the ureasecolorimetric method (Modified Urease-Berthelot Method) as described by Patton \& Crouch (1977). Albumin was determined using the bromocresol green (BCG)-dye binding reaction as described by Doumas et al., (1971). Total protein concentration was determined using the Biurets reaction as described by Gornall et al., (1949). Globulin was estimated indirectly by subtracting the albumin concentration from the total protein concentration. The albumin/globulin ratio was obtained by dividing the concentration of albumin by that of globulin according to Joshua et al., (2019).

2- Kidney Paraoxonase-1 (PON 1) activity was determined by an adaptation of the spectrophotometric method of Gan et al., (1991) with modifications according to Kumar\&Rizvi (2014).

3- Tumor Necrosis Factor a (TNF- $\alpha)$ in kidney tissue homogenate was determined by enzyme-linked immunosorbent assay (ELISA) according to the manufacturer's instruction. 


\section{Statistical analysis:}

Data were analyzed using IBM SPSS software package version 20.0. (Armonk, NY: IBM Corp). Quantitative data were described using mean and standard error. The significance of the obtained results was judged at the $5 \%$ level. Statistical comparisons between experimental groups were carried out using a one-way analysis of variance (ANOVA) test, followed by Tukey's multiple comparison post hoc test for pair-wise comparisons. Differences with values of $\mathrm{P}<0.05$ were considered statistically significant.

Results:

There is a high significance kidney $(P<0.001)$ in the group of Cisplatin compared to the control group and Gallic acid group, as well as, there is a high significance ( $P$ $<0.001$ ) in the group of Cisplatin + Gallic acid compared to Cisplatin group regarded to kidney function tests as shown in Table 1.

Table (1): Comparison between different studied groups according to kidney function tests

\begin{tabular}{ccccccc}
\hline & $\begin{array}{c}\text { Serum } \\
\text { Creatinine } \\
(\mathbf{m g} / \mathbf{d l})\end{array}$ & $\begin{array}{c}\text { Serum Urea } \\
(\mathbf{m g} / \mathbf{d l})\end{array}$ & $\begin{array}{c}\text { Albumin } \\
(\mathbf{g} / \mathbf{d l})\end{array}$ & $\begin{array}{c}\text { Total } \\
\text { Protein } \\
(\mathbf{g} / \mathbf{d l})\end{array}$ & $\begin{array}{c}\text { Globulin } \\
(\mathbf{g} / \mathbf{d l})\end{array}$ & $\begin{array}{c}\text { Albumin/ } \\
\text { Globulin ratio }\end{array}$ \\
\hline Group 1 (Control) & $0.55 \pm 0.03$ & $34.31 \pm 1.63$ & $3.47 \pm 0.10$ & $7.27 \pm 0.21$ & $3.80 \pm 0.23$ & $0.93 \pm 0.07$ \\
Group 2 (Gallic Acid) & $0.56 \pm 0.02$ & $41.72 \pm 2.20$ & $3.41 \pm 0.11$ & $7.16 \pm 0.24$ & $3.76 \pm 0.32$ & $0.99 \pm 0.14$ \\
Group 3 (Cisplatin) & $1.50^{\mathrm{ab}} \pm 0.22$ & $71.19^{\mathrm{ab}} \pm 4.11$ & $2.60^{\mathrm{ab}} \pm 0.10$ & $4.09^{\mathrm{ab}} \pm 0.18$ & $1.49^{\mathrm{ab}} \pm 0.14$ & $1.86^{\mathrm{ab}} \pm 0.21$ \\
$\begin{array}{c}\text { Group 4 (Cisplatin + } \\
\text { Gallic Acid) }\end{array}$ & $1.05^{\mathrm{ab}} \pm 0.09$ & $52.83^{\mathrm{ac}} \pm 3.02$ & $2.62^{\mathrm{ab}} \pm 0.14$ & $5.12^{\mathrm{abc}} \pm 0.28$ & $2.49^{\mathrm{abc}^{\mathrm{ab}} \pm 0.22}$ & $1.09^{\mathrm{c}} \pm 0.10$ \\
$\mathbf{P}$ & $<0.001^{* *}$ & $<0.001^{* * *}$ & $<0.001^{* * *}$ & $<0.001^{* * *}$ & $<0.001^{* * *}$ & $<0.001^{* * *}$ \\
\hline
\end{tabular}

Data were expressed by using (Mean \pm SE.).

p: $p$-value for comparing between the different studied groups.

a: Significant with Group 1 (Control) b: Significant with Group 2

c: Significant with Group $3 \quad$ : Statistically high significant at $p \leq 0.001$.

Table (2): Comparison between different studied groups according to TNF- $\alpha$ (ng/l), and Paraoxonase-1 (U/mg).

\begin{tabular}{ccc}
\hline & TNF- $\alpha$ (ng/l) & Paraoxonase-1 (U/mg) \\
\hline Group 1 (Control) & $87.97 \pm 1.67$ & $48.98 \pm 5.42$ \\
Group 2 (Gallic Acid) & $95.88 \pm 1.44$ & $50.29 \pm 2.62$ \\
Group 3 (Cisplatin) & $237.1^{\mathrm{ab}} \pm 6.41$ & $25.0^{\mathrm{ab}} \pm 3.39$ \\
Group 4 (Cisplatin + Gallic Acid) & $200.4^{\mathrm{abc}} \pm 9.13$ & $33.20 \pm 5.50$ \\
$\mathbf{p}$ & $<0.001^{* * *}$ & $0.001^{* * *}$
\end{tabular}

Data were expressed by using (Mean \pm SE.).

$\mathrm{p}$ : $\mathrm{p}$-value for comparing between the different studied groups.

a: Significant with Group 1 (Control) b: Significant with Group 2

c: Significant with Group $3 \quad$ : Statistically high significant at $p \leq 0.001$.

There is a high significance $(P<0.001)$ in the Cisplatin group when compared to the control group and Gallic acid group regarded to both TNF- $\alpha$ and Paraoxonase-1, and in the group of Cisplatin + Gallic acid when compared to Cisplatin group regarded to TNF-a, Table 2.

TNF- $\alpha$ levels were significantly increased in the Cisplatin group and the group of Cisplatin + Gallic acid in comparison with the control group and Gallic acid group; however, the TNF- $\alpha$ levels in group of Cisplatin + Gallic acid were significantly decreased compared with Cisplatin group, but still higher than those in the control group and
Gallic acid group, as shown in Figure 3. The levels of Paraoxonase-1 in the Cisplatin group were significantly decreased compared with the control group and Gallic acid group, and there was no significance between the Cisplatin group and group of Cisplatin + Gallic acid as shown in Figure 4.

Discussion

Cisplatin can induce everlasting nephrotoxicity in form of renal dysfunction and renal tubular cell injury. In addition, their energetic inflammatory response is also inspired by aggravating kidney dysfunctions. 


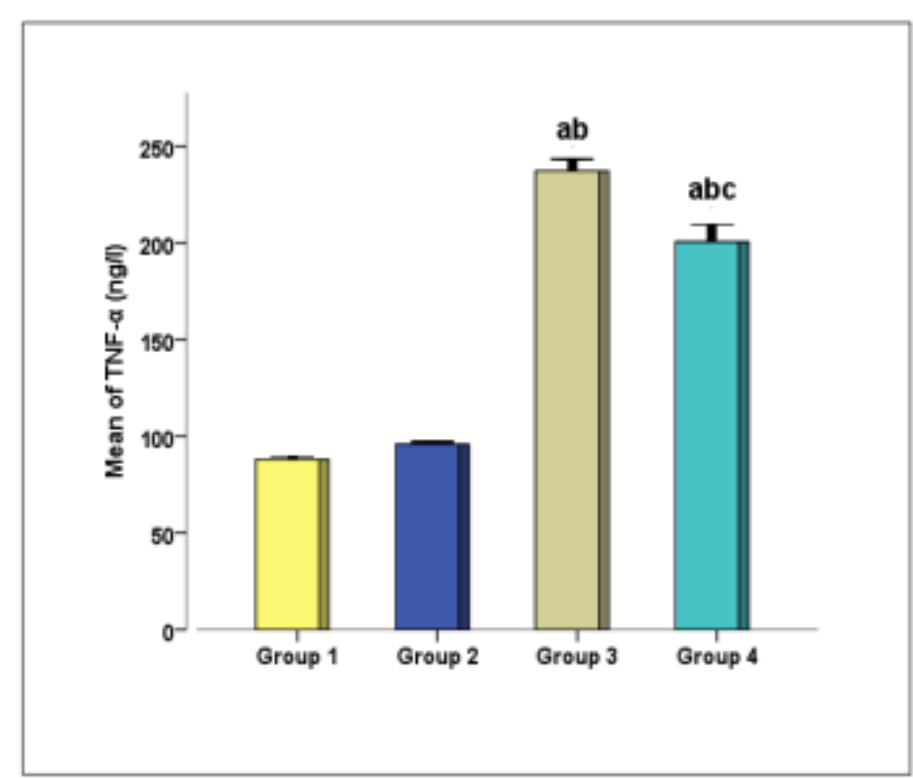

Figure (3): The mean of TNF- $\alpha$ in all studied groups.

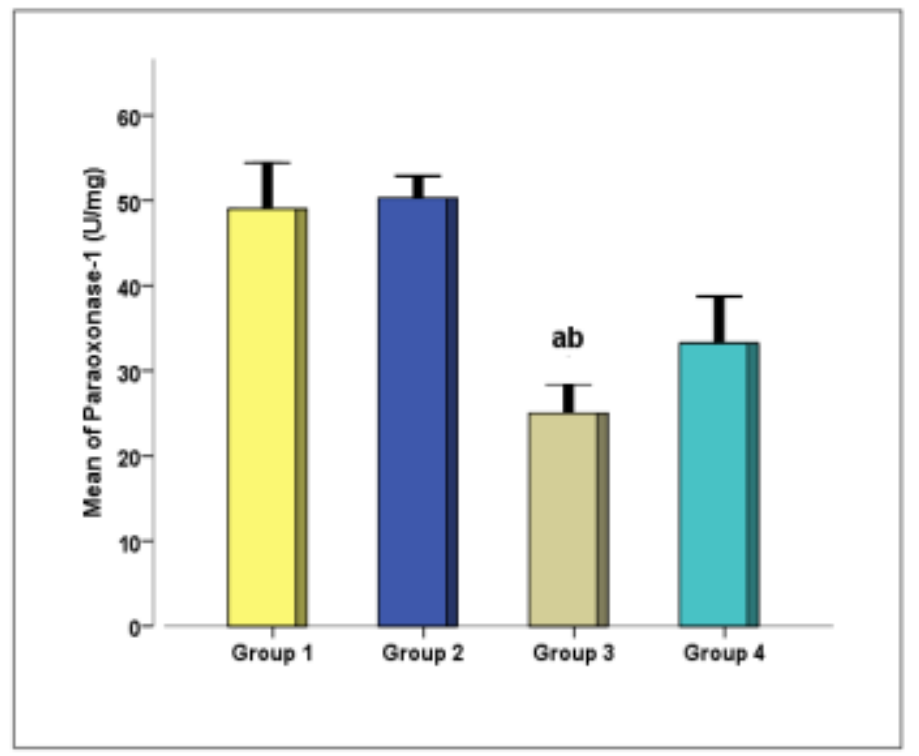

Figure (4): The mean of Paraoxonase-1 in all studied groups.

Cisplatin may additionally impose renal vasoconstriction through damage of the renal vasculature that led to blood flow reduction, inflicting ischemic kidney dysfunction and glomerular filtration functions (Monleón et al., 2017). Platinum compounds can exert their cellular and in specific renal toxicity through their covalent interaction with DNA purine bases, primarily in the N7 position, resulting in the formation of intrastrand and interstrand crosslinks which strongly correlated with the genotoxic effects of Cisplatin (Miller et al., 2010; Volarevic et al., 2019). The aquatic forms of Cisplatin are highly reactive with nucleophilic sites forming DNA-adducts. The major DNA lesions are the formation of intrastrand DNA adducts and interstrand crosslinks (ICLs) (Kim and Moon, 2012; Rocha et al., 2018). In the present study, the injection of Cisplatin induced kidney dysfunction with an increased level of kidney function tests such as creatinine and urea with decreased levels of total protein and albumin that coincident with Xiang et al. (2019) who reported that nephrotoxicity produces harmful effects in the body and increases the body's ion levels, serum creatinine, serum urea and blood urea nitrogen (BUN) with renal cell inflammation. Moreover, TNF- $\alpha$ has a central role in mediating renal injury through apoptosis induction and activation of a large network of chemokines and cytokines in the kidney (Yao et al., 2007). TNF- $\alpha$ can cause tubular cell death and tissue damage directly through TNF receptor type 1 (TNFR1) and indirectly by mounting a strong inflammatory response through TNF receptor type 2 (TNFR2). TNF- $\alpha$ is known to coordinate the activation of a large network of proinflammatory cytokines such as interleukin-1, 4, 6 (IL-1 $\beta$, IL-4, IL-6), transforming growth factor- $\beta 1$ (TGF- $\beta 1$ ) and monocyte chemotactic protein-1 (MCP-1) (Peres \& Cunha, 2013). On one side, the present work revealed that Cisplatin injection resulted in a significant increase in TNF- $\alpha$ level, while the pretreatment of rats with Gallic acid for 10 days before Cisplatin injection significantly decreased TNF- $\alpha$ level. This agrees with Yao who reported that TNF- $\alpha$-deficient mice are markedly protected against Cisplatin nephrotoxicity (Yao et al., 2007). In the present study, Cisplatin persuaded a significant decrease in the level of Paraoxonase-1 with an agreement with Dantoine et al. (1998) who reported that Paraoxonase activity was decreased in patients with some degree of renal insufficiency (chronic renal failure). On the other side, pretreatment of rats with Gallic acid for ten continuous days slightly increased Paraoxonase- 1 level compared with the Cisplatin group, but still statistically nonsignificant. Gallic acid's protective function is due to being a strong natural antioxidant that can inhibit reactive oxygen species (ROS) and preventing oxidative stress in tissues with increased exogenous antioxidants. ROS are specifically involved in oxidative damage to cellular macromolecules and alleviates free radicals by inactivating ROS enzymes and increasing the release of endogenous antioxidant enzymes (Kilic et al., 2018; Kohansal et al., 2019). So, the antioxidant activity of Gallic acid can be useful for a variety of diseases and significant detoxification of the kidney.

\section{Conclusion}

Cisplatin therapy has been shown to have a toxification effect on the kidney, while Gallic acid has been shown to protect rats' kidneys from Cisplatin-induced inflammatory and oxidative damage.

\section{References}

Akomolafe, S. F., Akinyemi, A. J., \& Anadozie, S. O. (2014). Phenolic Acids (Gallic and Tannic Acids) Modulate Antioxidant Status and Cisplatin Induced Nephrotoxicity in Rats. International Scholarly Research Notices, 2014, 1-8.

Binita G., Devika T., Nikhil G., Mallika V. (2009). Paraoxonase: A multifaceted biomolecule. ClinicaChimicaActa,410, 1-12.

Dantoine, T. F., Debord, J., Charmes, J. P., Merle, L., Marquet, P., Lachatre, G., and Leroux-Robert C. (1998). Decrease of 
serum paraoxonase activity in chronic renal failure. JASN, 9,2082-2088.

Dizaye, K. (2012). Alleviation of cisplatin-induced nephrotoxicity in rats by aqueous extract of Salvia officinalis leaves. Iraqi Journal of Pharmacy 12 (1), 48-55.

Doumas, B. T., Ard Watson, W., \& Biggs, H. G. (1971). Albumin standards and the measurement of serum albumin with bromcresol green. ClinicaChimicaActa, 31(1), 87-96.

El-Garhy A. M., Abd El-Raouf O. M, El-Sayeh B. M., et al. (2014). Ellagic acid anti-inflammatory and antiapoptotic potential mediate renoprotection in cisplatin nephrotoxic rats. Journal Biochemical and Molecular Toxicology, 28, 472-479.

El-Sayed E. M., Abd-Ellah M. F., Attia S. M. (2008). Protective effect of captopril Against cisplatin-induced nephrotoxicity in rats. Pakistan Journal of Pharmaceutical Sciences,21(3):255-261.

Francisco, J. R-O., Josune O., Ángel G., Concepción M. A. (2018). Oxidative Stress and Inflammation in Obesity and Metabolic Syndrome. Obesity Oxidative Stress and Dietary Antioxidants, 2018, 1-15.

Gan, K. N., Smolen, A., Eckerson, H. W., and La Du, B. N. (1991). Purification of human serum paraoxonase/arylesterase. Evidence for one esterase catalyzing both activities. Drug Metabolism and Disposition, 19 (1), 100-106.

Gornall, A. G., Bardawill, C. J., \& David, M. M. (1949). Determination of serum proteins by means of the biuret reaction. Journal of biological chemistry, 177 (2), 751-766.

Harel, M., Aharoni, A., Gaidukov. L., Brumshtein, B., Khersonsky, O., Meged, R., et al (2004). Structure and evolution of the serum paraoxonase family of detoxifying and anti-atherosclerotic enzymes. Nature Structural and Molecular Biology, 11,412-9.

Hassan, S., Shah, M., Yoon, S. C., Ullah, I., Kim, M. O., \& Yoon, J. (2013). Haptic guided virtual reality simulation for targeted drug delivery using nano-containers manipulation. Journal of Biomedical Nanotechnology, 9(7), 1190-1194.

Hussein, J., El-matty, D. A., El-Khayat, Z., \& Abdel-Latif, Y. (2013). Therapeutic role of coenzyme q10 in brain injury during experimental diabetes. Journal of Applied Pharmaceutical Science, 3(6), 213-217.

Joshua, P. E., Asomadu, R. O., Eze, C. S., Nnamani, I. V., Kingsley, C. O., Nweje-Anya, C. P., Patrick, V. J., \& Obe, S. A. (2019). Effect of Datura stramonium on Cyclophosphamideinduced Oxidative Stress in Albino Rats: Study on Kidney Markers. International Journal of Pharmacology, 15(8), 926-932.

Kahkeshani, N., Farzaei, F., Fotouhi, M., Alavi, S. S., Bahramsoltani, R., Naseri, R., Momtaz, S., Abbasabadi, Z., Rahimi, R., Farzaei, M. H., \& Bishayee, A. (2019). Pharmacological effects of gallic acid in health and disease: $A$ mechanistic review. Iranian Journal of Basic Medical Sciences, 22(3), 225-237.

Kilic, K., Sakat, M. S., Nur, F., Akdemir, E., Yildirim, S., Saglam, Y. S., \& Askin, S. (2018). Protective effect of gallic acid against cisplatin-induced ototoxicity in rats. Brazilian Journal of Otorhinolaryngology, 638, 1-8.

Kim, S. Y., and Moon, A. (2012). Drug-Induced Nephrotoxicity and Its Biomarkers. Biomolecules \& Therapeutics 20 (3), 268-272. Kohansal, P., Rajai, N., Dehpour, A. R., Rashidian, A., \&Shafaroodi, H. (2019). The protective effect of acute pantoprazole pretreatment on renal ischemia/reperfusion injury in rats. Fundamental and Clinical Pharmacology, 33(4), 405-411.

Kumar, D., \& Rizvi, S. I. (2014). Age-dependent paraoxonase 1 (PON1) activity and LDL oxidation in wistar rats during their entire lifespan. Scientific World Journal, 2014,1-6.

Larsen, K. (1972). Creatinine assay by a reaction-kinetic principle. ClinicaChimicaActa, 41, 209-217.
Miller, R. P., Tadagavadi, R. K., Ramesh, G., and Reeves, W. B. (2010). Mechanisms of Cisplatin Nephrotoxicity. Toxins, 2, 24902518.

Monleón, A. V., Barrallo, I. G., and González, I. C. (2017). Cisplatin Nephrotoxicity in A Patient With Metastatic Testicular Choriocarcinoma: A Case Report and Review of the Literature. Kidney Disease and Transplantation, 1(1), 1003-1007.

Ola-Davies, E. O., Olukole, S. G., \& Lanipekun, D. O. (2018). Gallic Acid Ameliorates Bisphenol A-Induced Toxicity in Wistar Rats. Iranian Journal of Toxicology, 12(4), 11-18.

Patton, C. J., \& Crouch, S. R. (1977). Spectrophotometric and Kinetics Investigation of the Berthelot Reaction for the Determination of Ammonia. Analytical Chemistry, 49(3), 464-469.

Peres, L. A. B., \& Cunha Júnior, A. D. da. (2013). Acute nephrotoxicity of cisplatin: Molecular mechanisms. Jornal Brasileiro de Nefrologia, 35, 332-340.

Primo-Parmo, S. L., Sorenson, R. C., Teiber, J. F., La Du, B. N. (1996). The human serum paraoxonase/arylesterase gene (PON1) is one member of a multigene family. Genomics,33, 498507.

Reckziegel, P., Dias, V. T., Benvegnú, D. M., Boufleur, N., Barcelos, R. C. S., Segat, H. J., Pase, C. S., dos Santos, C. M. M., Flores, É. M. M., \& Bürger, M. E. (2016). Antioxidant protection of gallic acid against toxicity induced by $\mathrm{Pb}$ in blood, liver and kidney of rats. Toxicology Reports, 3, 351-356.

Rocha, C. R. R., Silva, M. M., Quinet, A., Cabral-Neto, J. B., \& Menck, C. F. M. (2018). DNA repair pathways and cisplatin resistance: An intimate relationship. Clinics, 73 (1), 1-10.

Safaei, F., Mehrzadi, S., KhademHaghighian, H., Hosseinzadeh, A., Nesari, A., Dolatshahi, M., Esmaeilizadeh, M., Goudarzi, M. (2018). Protective effects of gallic acid against methotrexateinduced toxicity in rats. ActaChirurgicaBelgica, 118(3), 152-160.

Sánchez-González, P. D., López-Hernández, F. J., López-Novoa, J. M., and Morales, A. I. (2011). An integrative view of the pathophysiological events leading to cisplatin nephrotoxicity. Critical Reviews in Toxicology, 41 (10), 803-821.

Scalbert A., \& Williamson G. (2000). Dietary intake and bioavailability of polyphenols. Journal of Nutrition, 130(supplement 8):2073S-2085S.

Sri Laasya, T. P., Thakur, S., Poduri, R., \& Joshi, G. (2020). Current insights toward kidney injury: Decrypting the dual role and mechanism involved of herbal drugs in inducing kidney injury and its treatment. Current Research in Biotechnology, 2, 161-175.

Ueki M., Ueno M., Morishita J. et al. (2013). Curcumin ameliorates cisplatin-induced

nephrotoxicity by inhibiting renal inflammation in mice. $J$ BiosciBioeng, 115, 547-551.

Volarevic, V., Djokovic, B., Jankovic, M. G., Harrell, C. R., Fellabaum, C., Djonov, V., and Arsenijevic, N. (2019). Molecular mechanisms of cisplatin-induced nephrotoxicity: a balance on the knife edge between renoprotection and tumor toxicity. Journal of Biomedical Science,26 (1),1-14.

Xiang, X., Guo, C., Tang, C., Cai, J., and Dong, Z. (2019). Epigenetic Regulation in Kidney Toxicity: Insights From Cisplatin Nephrotoxicity. Seminars in Nephrology, 39(2), 152-158.

Yao, X., Panichpisal, K., Kurtzman, N., \& Nugent, K. (2007). Cisplatin Nephrotoxicity: A Review. The American journal of the medical sciences, 334(2), 115-124.

Zhu, S., Pabla, N., Tang, C., He, L., \& Dong, Z. (2015). DNA damage response in cisplatin-induced nephrotoxicity. Archives of Toxicology, 89 (12), $2197-2205$. 